\title{
Effect of Fiber Content on Abrasive Wear Behavior of Date Palm Leaf Reinforced Polyvinyl Pyrrolidone Composite
}

\author{
Jyoti R. Mohanty, ${ }^{1}$ Sankar N. Das, ${ }^{2}$ and Harish C. Das ${ }^{2}$ \\ ${ }^{1}$ Department of Mechanical Engineering, Veer Surendra Sai University of Technology, Burla, Sambalpur 768018, India \\ ${ }^{2}$ Department of Mechanical Engineering, SOA University, Bhubaneswar 751030, India \\ Correspondence should be addressed to Jyoti R. Mohanty; guddy95@gmail.com
}

Received 23 September 2013; Accepted 13 November 2013; Published 22 January 2014

Academic Editors: R. Hambli and Y. Lu

Copyright (c) 2014 Jyoti R. Mohanty et al. This is an open access article distributed under the Creative Commons Attribution License, which permits unrestricted use, distribution, and reproduction in any medium, provided the original work is properly cited.

\begin{abstract}
The effect of fiber contents on wear behavior of date palm leaf reinforced polyvinyl pyrrolidone (PVP/DPL) composites has been experimentally investigated. The test samples with fillers in 10, 20, 30, and $40 \%$ based on weight of fibers were prepared using injection molding. The optimum fiber content (i.e., $26 \mathrm{wt} \%$ ) for maximum mechanical strength of the composites was determined by regression analysis. The dry sliding wear tests were conducted for each composition at different sliding velocities $(0.392,0.471$, and $0.549 \mathrm{~m} / \mathrm{s})$ and sliding distances $(188,254$, and $376 \mathrm{~m})$ by applying normal loads of $5,10,15$, and $20 \mathrm{~N}$ using pin-on-disc wear testing machine. The specific wear rate, wear loss, and coefficient of friction were plotted against the normal load and sliding distance at all sliding velocities. The results reveal that incorporation of date palm leaf fibers leads to significant improvement in the wear resistance of composites up to optimum fiber content and then decreases as fiber content increases. Further, it is found that surface modification has significant effect on wear performance. Worn surfaces of some selected samples were studied by scanning electron microscopy to analyze the wear mechanism.
\end{abstract}

\section{Introduction}

Growing environmental awareness has focused considerable interest in the development of nonconventional materials which are renewable, recyclable, biodegradable, sustainable, and ecofriendly. Recently, organic lingocellulosic fibers reinforced in either thermoplastic or thermosetting polymers have attracted wide attention of many researchers and scientists around the world due to their advantages over conventional synthetic fibers such as glass fibers and carbon fibers. The thermoplastic polymers, in particular, have been proved as good matrix materials for production of natural fiber-reinforced thermoplastic composites due to their excellent chemical resistance, high damping properties, low noise emission, good processability, high impact resistance, damage tolerance, and above all high cost-performance ratio [1-3]. But, high level of moisture absorption, poor wettability, and insufficient adhesion between untreated natural fibers and the polymer matrix lead to debonding. However, proper surface modifications of natural fibers with suitable chemicals can overcome these problems to a certain extent.

Recently, characterization and properties of several natural fibers such as hemp, flax, jute, linen, kenaf, oil palm, and bamboo [4-12] have been explored in order to find their potential in numerous applications, for example, automobiles, furniture, packing, and construction. There are certain properties like viscoelastic and viscoplastic properties, timedependent behavior due to creep and fatigue, tribological properties, and so forth, where less attention has been devoted by the material designers. With regards to the usage of natural fiber-reinforced polymer (NFRP) composite in tribological application, surprisingly few works [13-18] have been reported in the tribology literature. As far as tribological behavior of date palm leaf fiber-reinforced thermoplastic composite is concerned, almost no works have been done till date. However, some investigations [19-24] have been undertaken to study various properties on this other than tribological property. Therefore, the objective of the present 


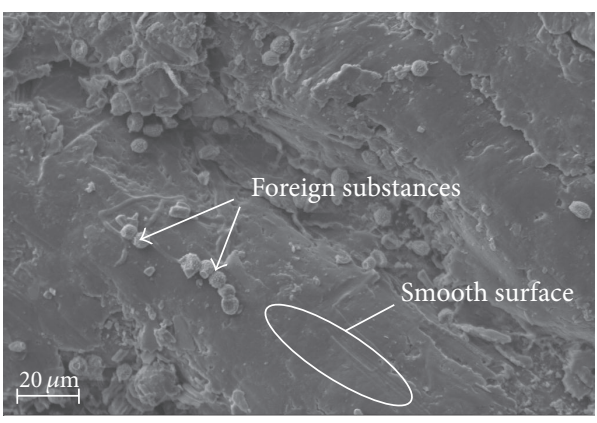

(a) Untreated date palm leaf fiber

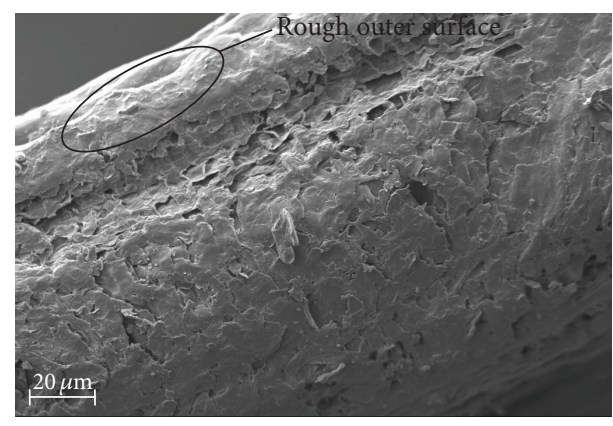

(b) Acrylic acid-treated date palm leaf fibers

FigurE 1: SEM images showing the difference of untreated and treated DPL fiber.

investigation is to study the effect of fiber content on abrasive wear behavior of date palm leaf reinforced polyvinyl pyrrolidone (PVP/DPL) composites.

\section{Materials and Method}

2.1. Raw Materials and Composite Fabrication. Polyvinyl pyrrolidone (PVP) was procured from Merck India, while date palm leaves were collected from Baleswar (Odisha), India, as forest waste. The chemicals such as sodium hydroxide, acrylic acid, and benzene of analytical grade were used without any further purification. All solutions were made in double distilled water.

The raw date palm leaf fibers $(1.5 \mathrm{~cm}$ long and $1 \mathrm{~mm}$ width) were washed with distilled water and dried at $70^{\circ} \mathrm{C}$ for $24 \mathrm{hrs}$ to remove the moistures. The fibers were first pretreated with $5 \% \mathrm{NaOH}$ solution for $1 \mathrm{~h}$ at $80^{\circ} \mathrm{C}$ and then given acrylic acid treatment as per the procedure described earlier [19] by the present authors. The alkaline pretreated fibers were swelled in a water/benzene solvent $\left(45 / 5 \mathrm{~cm}^{3}\right)$ for $15 \mathrm{~min}$ at $85^{\circ} \mathrm{C}$ and modified with $0.3 \mathrm{M}$ acrylic acid. The composite specimens for different tests were fabricated by mixing various weight percentages (e.g., 0\%, 10\%, 20\%, 30\%, and $40 \%$ ) of acrylic acid-treated DPL fibers with PVP matrix by injection molding.

It is worthwhile to mention here that, as a usual practice, surface treatments are given to almost all natural fibers in order improve interfacial adhesion and surface wettability of polar hydrophilic fiber with nonpolar hydrophobic matrix before fabrication of NFRP composites. However, it has been reported that [25] fiber strength decreases for most of the chemically treated NFRP composites due to breakage of the bond structure and disintegration of the noncellulosic materials. But, acrylation [26] treatment leads to strong covalent bond formation and the strength is enhanced marginally. Further, it has also been proved by the present authors [19] that acrylic acid-treated DPL fibers give highest tensile strength in comparison to other chemical treatment methods. Hence, in the present work, acrylic acid treatment has been adopted for the preparation of PVP/DPL composites specimens.

In order to study the surface property of DPL fibers, micrographs for both untreated and treated fibers were taken by scanning electron microscope (SEM) and presented

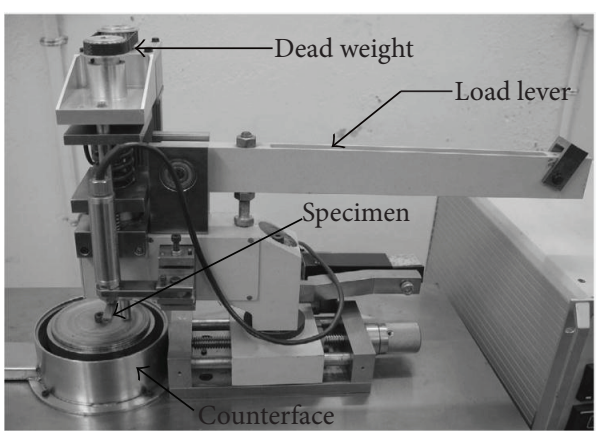

Figure 2: Pin-on-disc type wear testing machine.

in Figures 1(a) and 1(b), respectively. It has been found from Figure 1(a) that a lot of foreign substances are trapped on the fiber surface before chemical treatment. However, after the treatment, the surface of date palm leaf fiber is rougher than that of untreated one and free from foreign substances (Figure 1(b)). It clearly indicates that acrylic acid treatment eliminates hemicelluloses and soluble lignin from the fiber surface thereby enhancing the fiber surface wettability between the PVP matrix and DPL fiber.

2.2. Mechanical Properties. Tensile properties of the composite were measured on a servohydraulic static testing machine (INSTRON 3382) with load cell of $5 \mathrm{kN}$ as per ASTM D 638 standard. Three identical samples were tested at each fiber loading (i.e., $0 \%, 10 \%, 20 \%, 30 \%$, and $40 \%$ ) at a cross head speed of $2 \mathrm{~mm} / \mathrm{min}$ out of which average readings were taken. Flexural strengths were measured on the same machine at each fiber loading using 3-point bending method as per ASTM D 790 standard.

Impact strengths of the composite samples were obtained on a pendulum type Izod Impact tester as per ASTM D 256. Microhardness measurement was made using Leitz Microhardness tester equipped with a monitor and a microprocessor-based controller, with a load of $0.245 \mathrm{~N}$ and a loading time of 20 seconds. About five readings were taken on each sample and the average value was taken.

2.3. Abrasive Wear Test. Wear and frictional tests were conducted under multipass two-body abrasion condition on a pin-on-disc (POD) type wear testing machine (Figure 2) 
TABLE 1: Test parameters for dry sliding wear test.

\begin{tabular}{|c|c|c|c|}
\hline $\begin{array}{l}\text { Fiber weight } \\
\text { Fraction }(\%)\end{array}$ & $\begin{array}{c}\text { Load } \\
(\mathrm{N})\end{array}$ & $\begin{array}{c}\text { Sliding speed } \\
(\mathrm{m} / \mathrm{s})\end{array}$ & $\begin{array}{l}\text { Sliding distance } \\
(\mathrm{m})\end{array}$ \\
\hline \multirow{4}{*}{0} & 5 & 0.392 & 188.55 \\
\hline & 10 & 0.471 & 254.32 \\
\hline & 15 & 0.549 & 314.20 \\
\hline & 20 & & 376.00 \\
\hline \multirow{4}{*}{10} & 5 & 0.392 & 188.55 \\
\hline & 10 & 0.471 & 254.32 \\
\hline & 15 & 0.549 & 314.20 \\
\hline & 20 & & 376.00 \\
\hline \multirow{4}{*}{20} & 5 & 0.392 & 188.55 \\
\hline & 10 & 0.471 & 254.32 \\
\hline & 15 & 0.549 & 314.20 \\
\hline & 20 & & 376.00 \\
\hline \multirow{4}{*}{26} & 5 & 0.392 & 188.55 \\
\hline & 10 & 0.471 & 254.32 \\
\hline & 15 & 0.549 & 314.20 \\
\hline & 20 & & 376.00 \\
\hline \multirow{4}{*}{30} & 5 & 0.392 & 188.55 \\
\hline & 10 & 0.471 & 254.32 \\
\hline & 15 & 0.549 & 314.20 \\
\hline & 20 & & 376.00 \\
\hline \multirow{4}{*}{40} & 5 & 0.392 & 188.55 \\
\hline & 10 & 0.471 & 254.32 \\
\hline & 15 & 0.549 & 314.20 \\
\hline & 20 & & 376.00 \\
\hline
\end{tabular}

as per ASTM G99-95 standard. A load cell was adopted in proper position to measure frictional forces, while a digital friction indicator was integrated directly to the load cell to capture the frictional readings.

Cylindrical (pin) type specimen of length $35 \mathrm{~mm}$ and diameter of $10 \mathrm{~mm}$ was slid against a rotating disc (EN 31 Steel disc) of $120 \mathrm{~mm}$ diameter, on which abrasive paper of 400 grade (grit size $\approx 23 \mu \mathrm{m}$ ) was mounted using doublesided adhesive tape. The specimens under test were fixed to the sample holder. The track diameter was changed after each test selecting a fresh one for new specimen. For each test, new abrasive paper was used and the specimen was abraded for total sliding distance of $376 \mathrm{~m}$. The different test parameters for dry sliding wear test have been presented in Table 1 .

Frictional force at the sliding interface was measured at every $5 \mathrm{~s}$ using load cell mounted on the load lever that holds the specimen. The frictional coefficient was determined using (1). Each test was repeated for three times and the average of each measurement was taken. Consider

$$
\mu=\frac{F_{f}}{F_{n}},
$$

where $F_{f}$ is the friction force $(\mathrm{N})$, and $F_{n}$ is the normal load $(\mathrm{N})$.

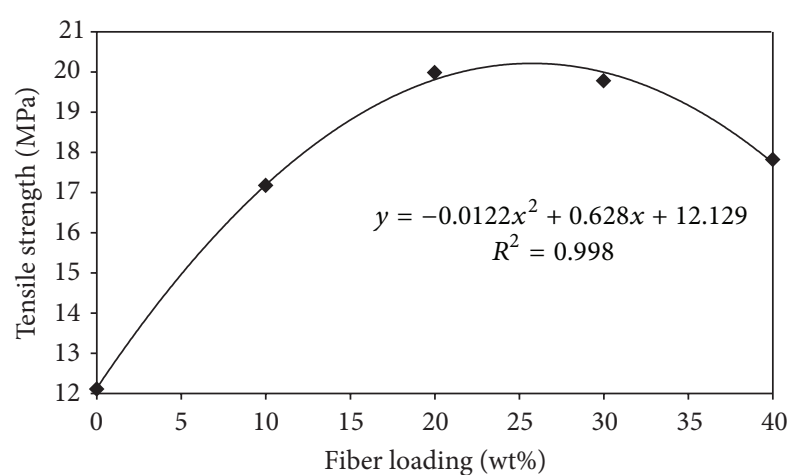

FIGURE 3: Tensile strengths of PVP/DPL biocomposite at different $\mathrm{wt} \%$ of fiber loadings.

After measuring the initial weight of test specimen, it was subjected to run on the counter disc for a particular test condition. The worn specimens were cleaned by tissue paper soaked with acetone and then by dry air before measuring the weight. Weight of the specimens was measured by an electronic balance (Shimadzu, Japan, AUW. 220D) with $0.01 \mathrm{mg}$ least count. The difference in the weight measured before and, after each test gives the weight loss of the composite specimen. The specific wear rate $\left(W_{s}\right)$ was calculated by the following equation:

$$
W_{s}=\frac{\Delta W}{\rho F_{n} S_{d}} \mathrm{~m}^{3} / \mathrm{Nm},
$$

where $F_{n}$ is the normal load (N), $S_{d}$ the sliding distance $(\mathrm{m})$, $\Delta W$ the weight loss $(\mathrm{kg})$, and $\rho$ the density of the composite $\left(\mathrm{kg} / \mathrm{m}^{3}\right)$.

2.4. Examination of Worn Surfaces. Scanning electron microscope (SEM) model JEOL, JSM-840 was used to analyze the worn surfaces' morphology. Before taking the SEM image, the specimen surfaces were coated with a thin layer of gold using an ion sputtering device (JEOL, JFC-1600).

\section{Results and Discussions}

As reported in the review work conducted by Shalwan and Yousif [18] regarding the effect of volume (or weight) fraction of fiber on tensile strength of NFRP composites, it is found that the strength increases proportionately with the increase in volume fraction and after reaching a specific value, it further deteriorates. In the present case, also almost the same trend is observed when the measured tensile strength data of synthesized PVP/DPL composites are plotted against different weight percentages of acrylic acid-treated DPL fibers (Figure 3).

In order to get the optimum weight percentage theoretically, the tensile strength data are fitted with weight percentages of fibers by regression analysis. As depicted in Figure 3 , the data fit well by 2 nd degree polynomial with regression coefficient $\left(R^{2}\right.$-value) of 0.998 which gives the optimum strength (i.e., $20.21 \pm 1.56 \mathrm{MPa}$ ) at $26 \mathrm{wt} \%$ of fiber 


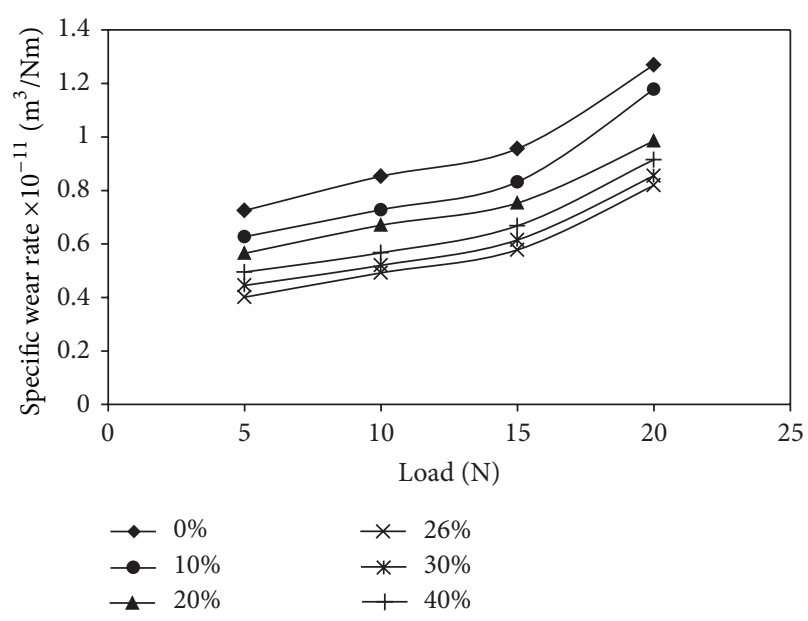

(a)

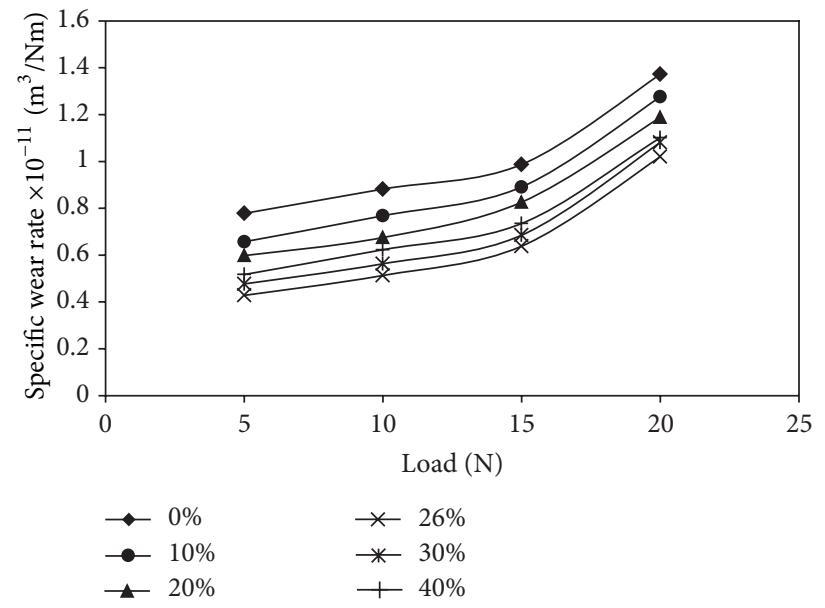

(b)

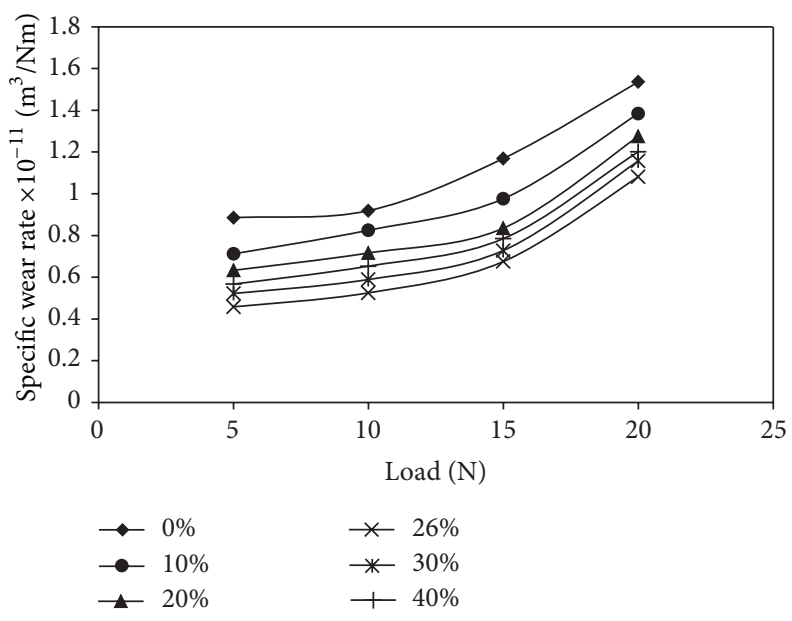

(c)

FIGURE 4: Effect of specific wear rate on variations of load of PVP/DPL composite at (a) $0.392 \mathrm{~m} / \mathrm{s}$, (b) $0.471 \mathrm{~m} / \mathrm{s}$, and (c) $0.549 \mathrm{~m} / \mathrm{s}$.

loading. Compared to neat PVP, 59\% increase in tensile strength has been observed for PVP/DPL composites at optimum fiber loading.

After obtaining the optimum weight percentage of DPL fiber (i.e., 26\%) in PVP matrix for maximum tensile strength, composite specimens were fabricated on this fiber loading also to find out the other mechanical properties such as flexural strength, impact strength, and hardness. The above properties of the composite were measured at all fiber loadings (i.e., $0 \%, 10 \%, 20 \%, 26 \%, 30 \%$, and $40 \%$ ) as per the procedure given in the previous section and presented in Table 2. From the results, it is evident that, similar to tensile strength, flexural strength, and impact strength first increase with fiber loading, and reaching maximum values at optimum fiber loading, then decrease. However, microhardness of the composites increases with fiber loading due to the incorporation of hard brittle fibers in soft matrix.

In order to study the tribological behavior of PVP/DPL composite, the specimens were fabricated at different fiber loadings for abrasive wear test by injection molding as described in the previous section. The variations of specific

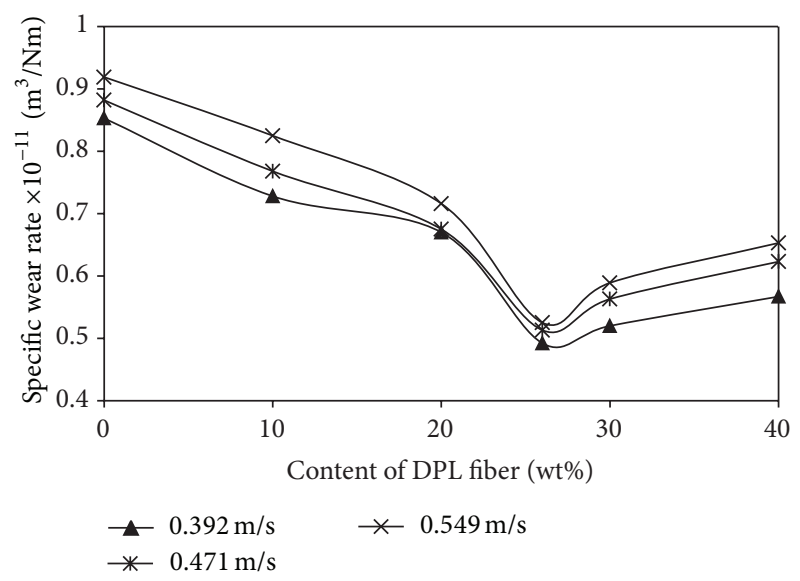

FIGURE 5: Comparison of specific wear rate with fiber loading.

wear rates with load and fiber content of PVP/DPL composite at sliding velocities of $0.392,0.471$, and $0.549 \mathrm{~m} / \mathrm{s}$ have been presented in Figures 4 and 5, respectively. Figure 4 shows the 


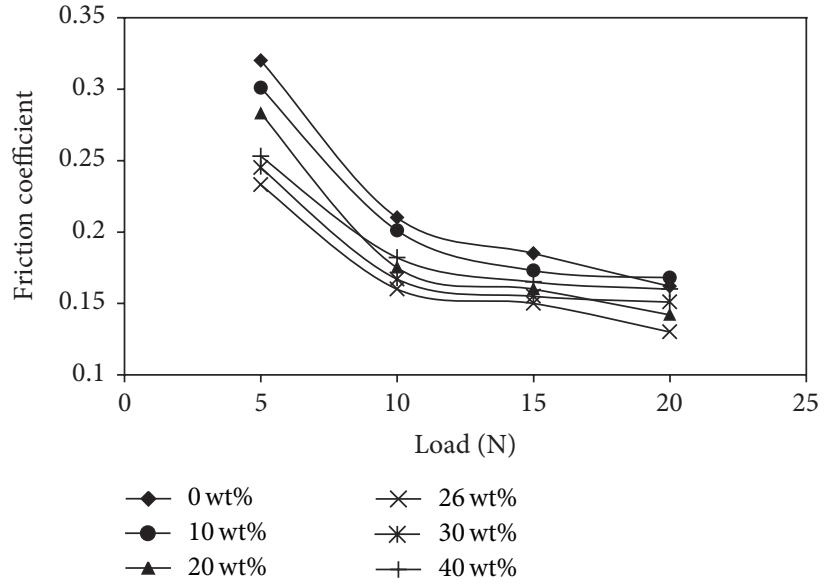

(a)

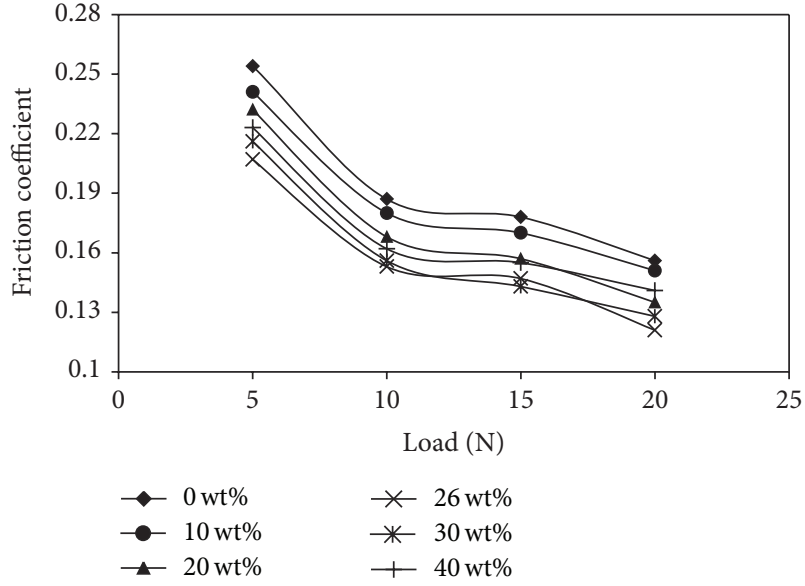

(b)

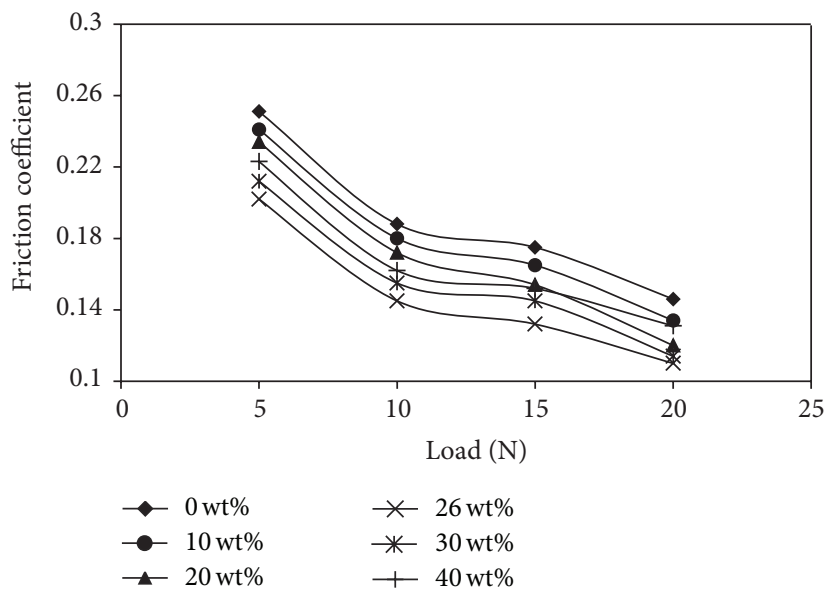

(c)

FIGURE 6: Effect of friction coefficient on variations of load of PVP/DPL composite at $0.392 \mathrm{~m} / \mathrm{s}$, (b) $0.471 \mathrm{~m} / \mathrm{s}$, and (c) $0.549 \mathrm{~m} / \mathrm{s}$.

dependence of specific wear rate on applied load for $376 \mathrm{~m}$ sliding distance. It is found that specific wear rate increases as applied load increases at different sliding speeds $(0.392-$ $0.549 \mathrm{~m} / \mathrm{s}$ ) for both neat PVP (i.e., $0 \mathrm{wt} \%$ ) and its composites. Similar results were also reported earlier $[27,28]$ in case of natural fiber-reinforced polymer composites. The reason for increasing specific wear rate with applied load is that, as the fiber content increases, the matrix transfers and distributes the applied load onto the fibers which in turn increases the wear resistance of the composite. However, it occurs up to a particular fiber loading (i.e., 26 wt\%) as is evident from the figure. When the fiber content increases beyond the optimum value, DPL fibers get agglomerated as a result the interaction between DPL fibers and PVP matrix is reduced. This causes debonding of fibers from the matrix. Hence, at higher fiber loading, the interfacial adhesion between the fiber and matrix is not sufficient enough to resist sliding force resulting in higher wear rate. Further, it is observed that, at lower speed (i.e., $0.392 \mathrm{~m} / \mathrm{s}$ ), the specific wear rate is somehow less in comparison to higher speeds (i.e., 0.471 and $0.549 \mathrm{~m} / \mathrm{s}$ ) for all weight percentages of DPL fibers (Figures 4(b) and 4(c)). Comparing the specific wear rate of PVP/DPL composite at different fiber loadings (Figure 5), it is observed that, as fiber content increases wear rate decreases, after reaching a minimum value at $26 \mathrm{wt} \%$ of DPL fiber, then it further increases. Shalwan and Yousif [18] have pointed out that there is no remarkable correlation between the mechanical and tribological performance of major polymeric composites. But, in the present work, it is found that both the mechanical and tribological properties of PVP/DPL composite show optimum value at $26 \mathrm{wt} \%$ of fiber loading.

The effect of friction coefficients on variations of applied load at all sliding speeds have been presented in Figure 6 . From the figure, it is observed that friction coefficient decreases as applied load increases for neat PVP and its composites for all sliding speeds. This is because, at low load, increased value of friction coefficient is due to mechanical interlocking of asperities at the interface. As the applied load increases, temperature at the contact surface between specimen and counterface also increases which causes heating of the contact surface. Thus, the friction coefficient decreases due to the micromelting and mechanical deterioration caused by friction heat at higher loads. Similar results have been obtained for sugarcane reinforced polyester composite by 


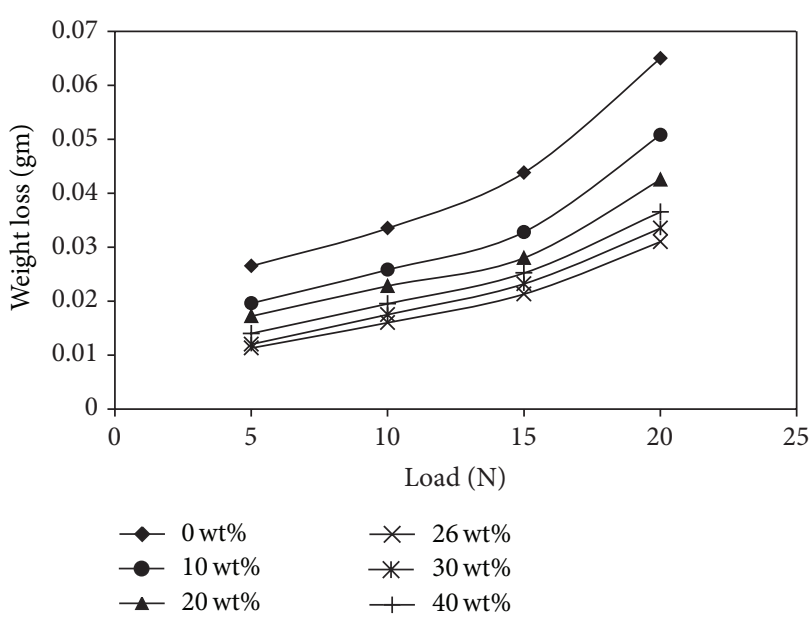

(a)

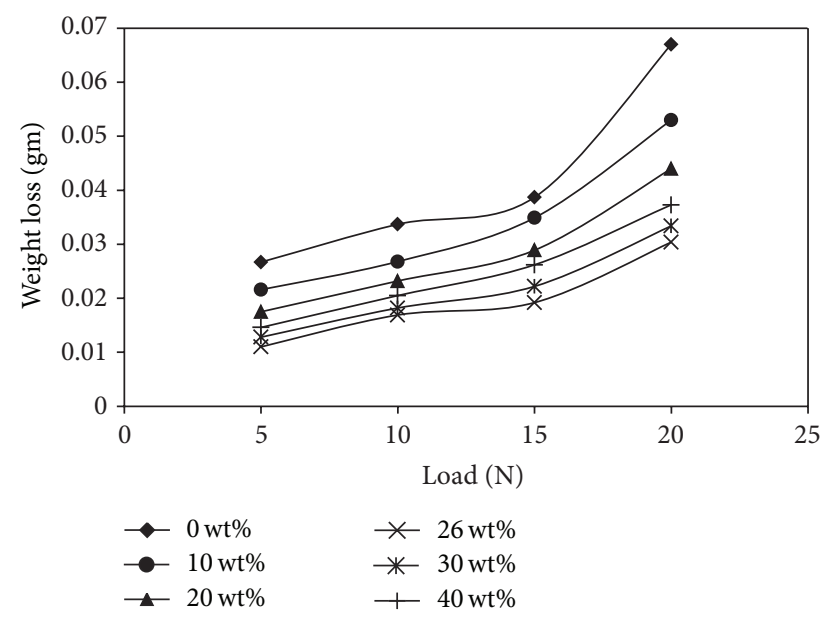

(b)

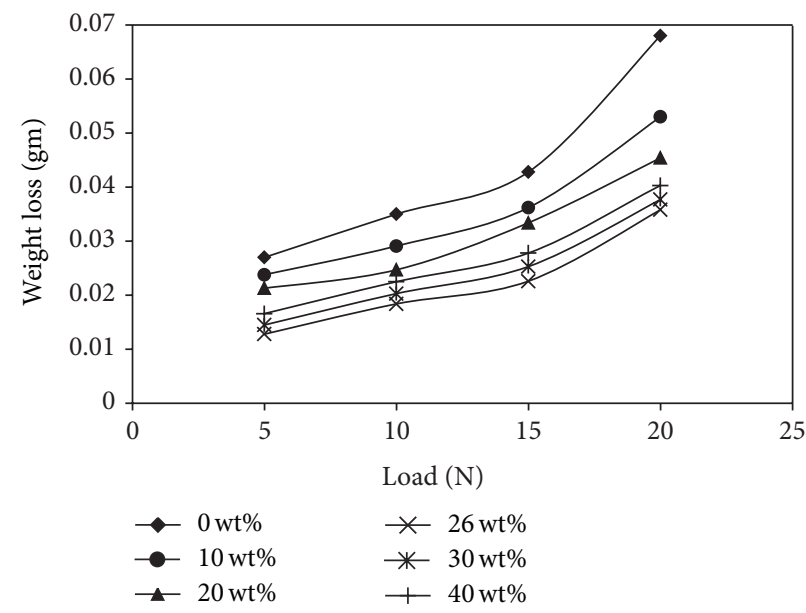

(c)

FIGURE 7: Effect of weight loss on variations of load of PVP/DPL composite at (a) $0.392 \mathrm{~m} / \mathrm{s}$, (b) $0.471 \mathrm{~m} / \mathrm{s}$, and (c) $0.549 \mathrm{~m} / \mathrm{s}$.

EI-Tayeb [15]. Therefore, from the above results, it can be concluded that addition of date palm leaf fiber in the composite reduces the friction coefficients which is a good sign of PVP/DPL composite for tribological applications.

Weight loss as a function of load at different sliding speeds has been presented in Figure 7. As is evident from the figure, weight loss of the composites increases with the increase in applied load. This is due to the deeper grooving and more material removal from the sample with increasing load. The PVP matrix shows the highest weight loss because abrasive particles penetrate deeper into the softer matrix forming a series of tracks. Addition of fibers into the matrix increases fiber-matrix adhesion which reduces the material removal. It continues up to $26 \mathrm{wt} \%$ of fiber loading, which is the optimum value of DPL fiber in PVP matrix for the composite that provides the higher wear resistance. This may be due to the proper combination of various dominating factors such as tensile properties, hardness, toughness, and above all the fiber-matrix adhesion. In case of higher fiber contents above the optimum value, internal slippage of chain molecules increases which lowers the wear resistance and hence there is an increase in weight loss in comparison to $26 \mathrm{wt} \% \mathrm{PVP} / \mathrm{DPL}$ composites.

The variation of specific wear rate and weight loss with sliding distance of PVP/DPL composites have been presented in Figures 8 and 9, respectively. From Figures $8(a)-8(c)$ it is observed that specific wear rate is decreasing proportionately with the function of sliding distances and sliding velocities. At the initial stage of sliding distance, the range of specific wear rate is high. However, it reaches an almost steady state at a distance of about $250 \mathrm{~m}$. This is attributed to the multipass abrasion condition in which the severity of the abrasives decreases with repeated passes causing minimum wear for maximum test duration. In other words, there is less removal of material at longer sliding distances.

Examining the weight loss of PVP/DPL composite (Figure 9), it is found that weight loss increases with increasing of sliding distance due to progressive material removal with sliding velocities. This is because of the fact that the temperature of contact region during abrasion increases with the increase of sliding distance, which deteriorates the bonding and thereby causing material removal. Further, it 
TABLE 2: Mechanical properties of PVP/DPL composites at different fiber loadings.

\begin{tabular}{lccccc}
\hline wt\% of DPL fiber & $\begin{array}{c}\text { Tensile strength } \\
(\mathrm{MPa})\end{array}$ & $\begin{array}{c}\text { Flexural strength } \\
(\mathrm{MPa})\end{array}$ & $\begin{array}{c}\text { Impact strength } \\
\left(\mathrm{kJ} / \mathrm{m}^{2}\right)\end{array}$ & $\begin{array}{c}\text { Hardness } \\
(\mathrm{Hv})\end{array}$ & $\begin{array}{c}\text { Specific wear rate } \times 10^{-11} \\
\left(\mathrm{~m}^{3} / \mathrm{Nm}\right)\end{array}$ \\
\hline 0 & $12.67 \pm 0.63$ & $19.21 \pm 1.01$ & $0.98 \pm 0.01$ & 64.0 & 0.919 \\
10 & $15.17 \pm 0.94$ & $22.55 \pm 0.97$ & $1.17 \pm 0.03$ & 66.5 & 0.825 \\
20 & $19.82 \pm 1.24$ & $31.59 \pm 2.01$ & $1.29 \pm 0.06$ & 68.0 & 0.716 \\
26 & $20.21 \pm 1.56$ & $31.71 \pm 1.56$ & $1.32 \pm 0.12$ & 71.4 & 0.525 \\
30 & $18.19 \pm 0.98$ & $28.89 \pm 1.13$ & $1.30 \pm 0.11$ & 72.0 & 0.589 \\
40 & $17.01 \pm 1.02$ & $21.11 \pm 0.98$ & $1.10 \pm 0.04$ & 74.5 & 0.653 \\
\hline
\end{tabular}

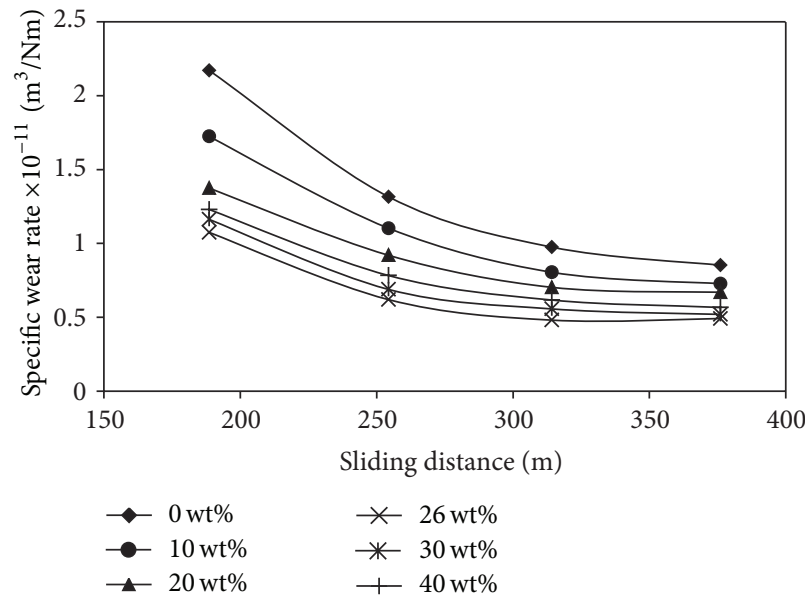

(a)

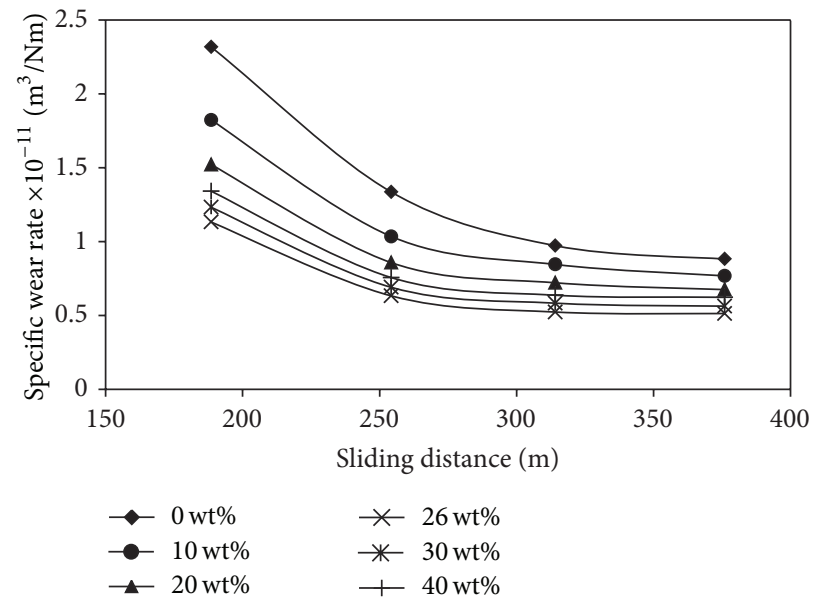

(b)

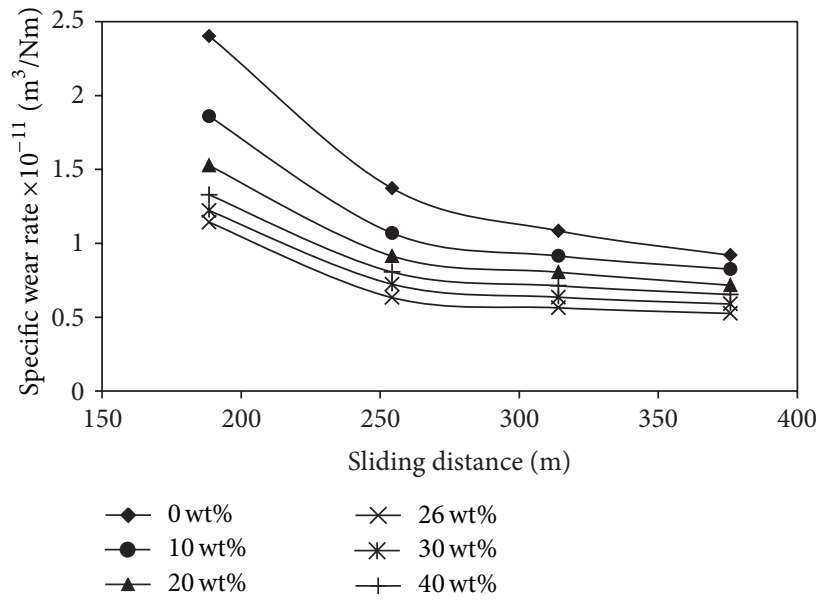

(c)

FIGURE 8: Effect of specific wear rate on variations of sliding distance (at $10 \mathrm{~N}$ ) of PVP/DPL composite at (a) $0.392 \mathrm{~m} / \mathrm{s}$, (b) $0.471 \mathrm{~m} / \mathrm{s}$, and (c) $0.549 \mathrm{~m} / \mathrm{s}$

is found that date palm leaf fiber-reinforced PVP composite having $26 \mathrm{wt} \%$ exhibits minimum weight loss at all sliding speeds.

Figure 10 illustrates typical effects of the surface modification of DPL fiber on the abrasive wear of the composite at $10 \mathrm{~N}$ load and $0.549 \mathrm{~m} / \mathrm{s}$ sliding speed. It is clear that acrylic acid modification of DPL fibers significantly improves the abrasive wear property of the composites showing minimum weight loss at $26 \mathrm{wt} \%$ of DPL fiber. Further, it is found that there is an $11 \%$ decrease in weight loss of surface-modified PVP/DPL composite in comparison to unmodified one at optimum fiber loading which clearly indicates the effect of surface modification on wear property.

The morphology of worn surfaces of PVP/DPL composites is analyzed based on SEM features (Figures 11(a)-11(c)) for selected samples (at optimum fiber loading) tested under a load of $10 \mathrm{~N}$ and sliding distance of $376 \mathrm{~m}$ at all the three sliding velocities. 


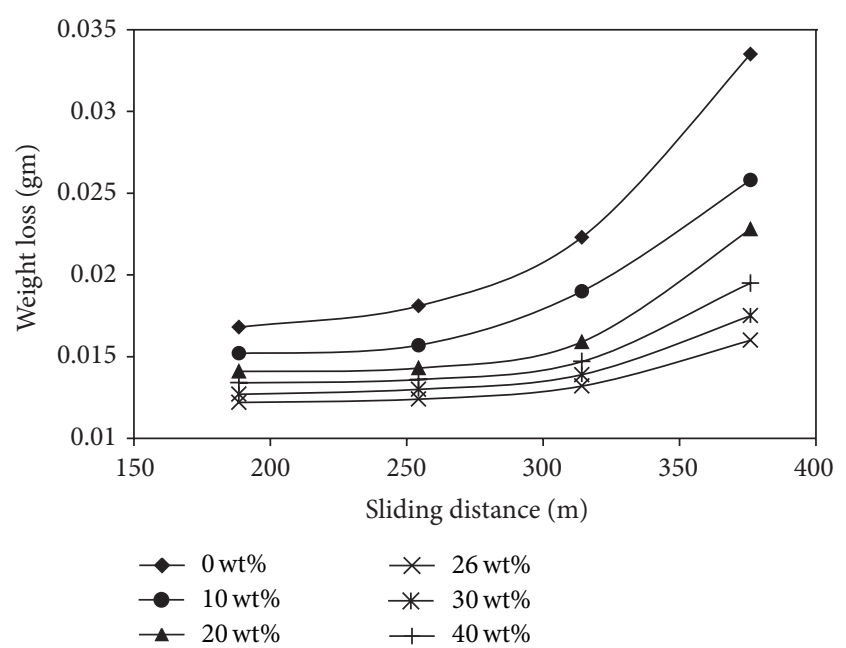

(a)

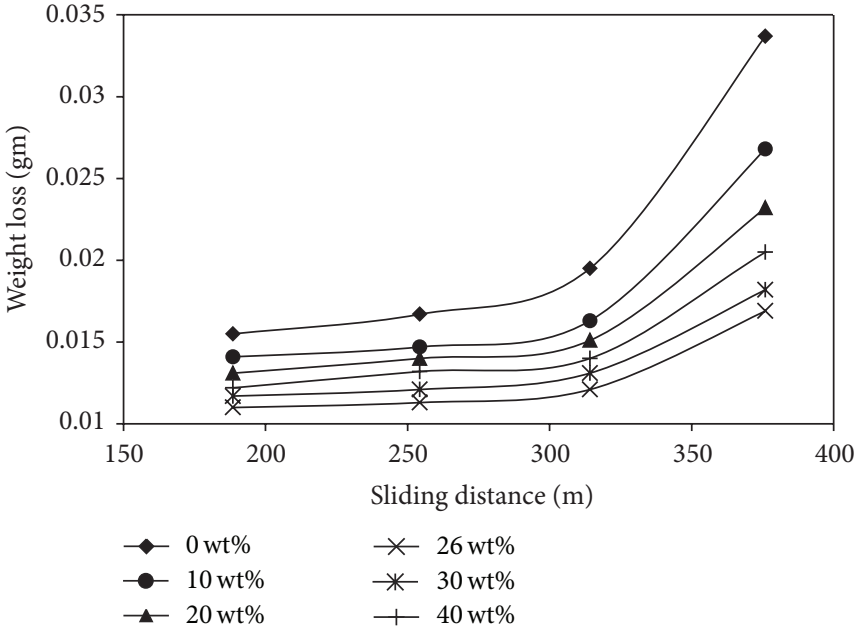

(b)

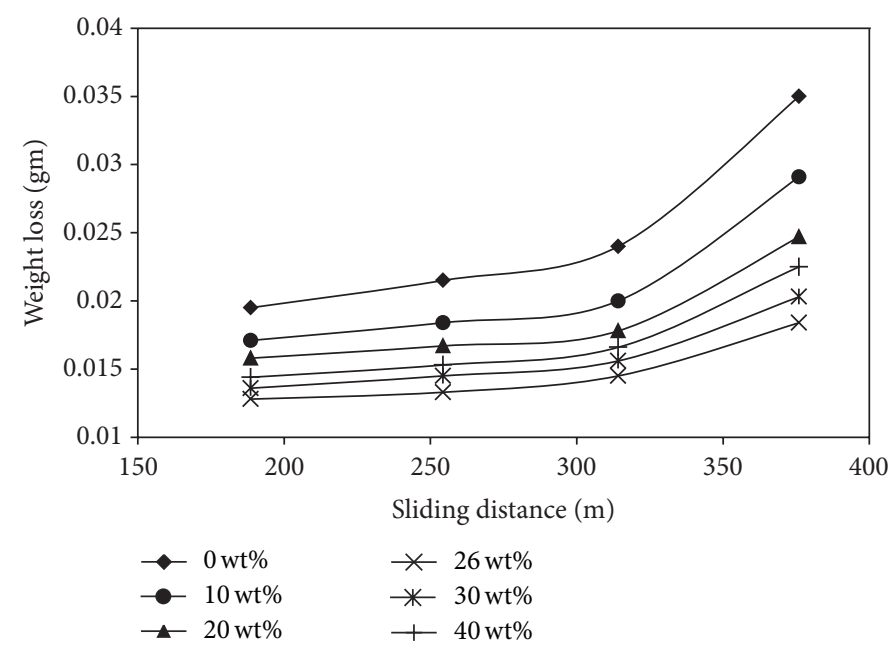

(c)

FIGURE 9: Effect of weight loss on variations of sliding distance (at $10 \mathrm{~N}$ ) of PVP/DPL composite at (a) $0.392 \mathrm{~m} / \mathrm{s}$, (b) $0.471 \mathrm{~m} / \mathrm{s}$, and (c) $0.549 \mathrm{~m} / \mathrm{s}$.

From the figure, it is observed that the worn surface of samples tested at low speed (Figure 11(a)) is somehow smoother than those tested at higher speeds (Figures 11(a) and 11(b)), with no sign of fiber fracture, major cracks, and pits. The mechanism of wear at low velocities is characterized by microcracking, detachment of fiber, signs of debris formation (Figure 11(a)), and matrix breakage (Figure 11(b)). At higher velocity, the damage caused to the sample is severe in the form of major cracks, fiber fracture, matrix breakage (Figures 11(b) and 11(c)), and formation of pits (Figure 11(c)) causing greater wear of the material. In addition to that debonding is also observed at medium and high speeds (Figures 11(b) and 11(c)). Further, almost rough surfaces are noticed due to the high material removal process which assisted to increase the wear rate at longer sliding velocities.

\section{Conclusions}

The effect of fiber content on friction and wear properties of PVP/DPL composites has been investigated. From the

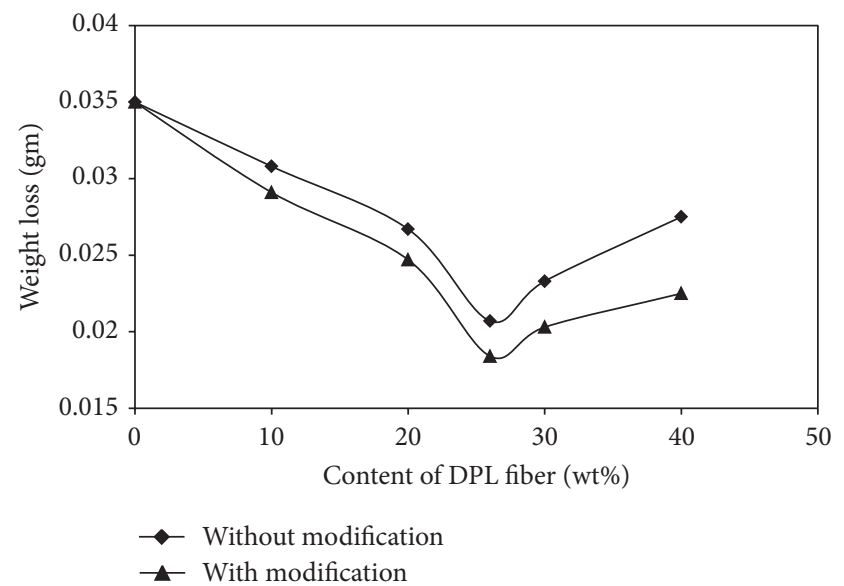

FIGURE 10: Comparison of weight loss with fiber loading.

results, it is observed that incorporation of date palm leaf fillers significantly improves the wear properties of PVP/DPL 


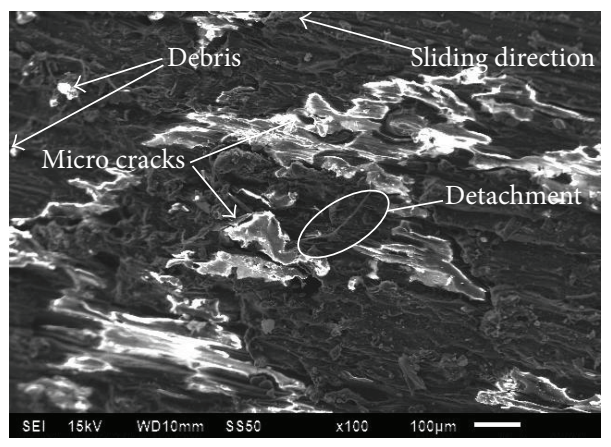

(a)

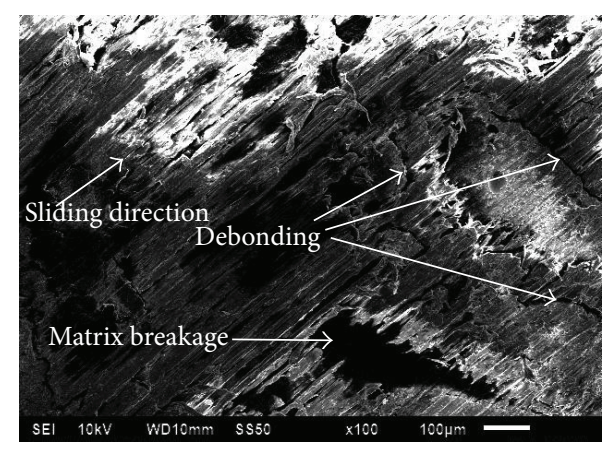

(b)

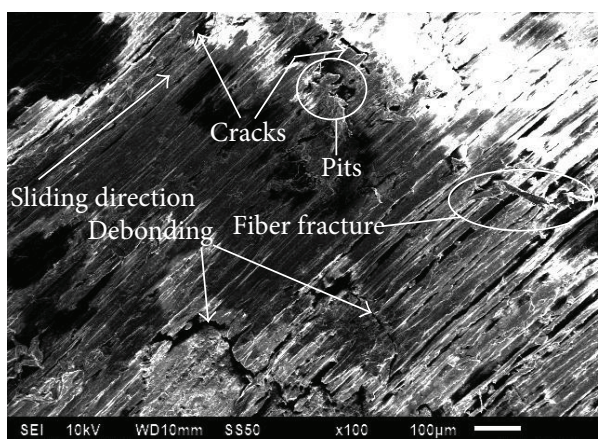

(c)

Figure 11: SEM micrographs of worn surfaces (at $10 \mathrm{~N}$ ) of $26 \mathrm{wt} \%$ PVP/DPL composite (a) $0.392 \mathrm{~m} / \mathrm{s}$, (b) $0.471 \mathrm{~m} / \mathrm{s}$, and (c) $0.549 \mathrm{~m} / \mathrm{s}$.

composites up to a certain fiber content (i.e., 26 wt\%). After that the wear properties decrease similar to mechanical properties. Specific wear rate and weight loss of the composites increase with the increase in the normal load and sliding distances at all sliding velocities. Further, it is found that the coefficient of friction of the composites decreases as applied load increases at all sliding velocities. Lowest coefficient of friction in $26 \mathrm{wt} \%$ filled PVP/DPL composites indicates their higher wear resistance. Further, it is found that surface modification has significant effect on wear performance and it increases the wear resistance of PVP/DPL composites. From the morphology of worn surfaces, it is observed that the wear mechanism of PVP/DPL composites at low sliding velocity is dominated by fiber fracture, matrix breakage, and microcracking, whereas, at high velocities, major cracks, debonding, and formation of pits are the predominant wear mechanisms. Finally, it can be concluded that there is a correlation between the mechanical and tribological properties of PVP/DPL composites showing optimum values at $26 \mathrm{wt} \%$ of fiber loading.

\section{Conflict of Interests}

The authors declare that there is no conflict of interests regarding the publication of this paper.

\section{References}

[1] S. A. R. Hashmi, S. Neogi, A. Pandey, and N. Chand, "Sliding wear of PP/UHMWPE blends: effect of blend composition," Wear, vol. 247, no. 1, pp. 9-14, 2001.
[2] C. M. Pooley and D. Tabor, "Friction and molecular structure: the behavior of some thermoplastics," Proceedings of Royal Socity, London A, vol. 329, pp. 251-274, 1972.

[3] J. K. A. Amu zu, B. J. Briscoe, and D. Tabor, "Polymers as bearing and lubricants: aspects of fundamental research," in Advances in Tribology, Institute of Mechanical Engineers, pp. 59-62, London, UK, 1978.

[4] S. V. Joshi, L. T. Drzal, A. K. Mohanty, and S. Arora, "Are natural fiber composites environmentally superior to glass fiber reinforced composites?" Composites Part A, vol. 35, no. 3, pp. 371-376, 2004.

[5] A. S. Virk, W. Hall, and J. Summerscales, "Failure strain as the key design criterion for fracture of natural fibre composites," Composites Science and Technology, vol. 70, no. 6, pp. 995-999, 2010.

[6] P. Saha, S. Manna, S. R. Chowdhury, R. Sen, D. Roy, and B. Adhikari, "Enhancement of tensile strength of lignocellulosic jute fibers by alkali-steam treatment," Bioresource Technology, vol. 101, no. 9, pp. 3182-3187, 2010.

[7] B. F. Yousif and H. Ku, "Suitability of using coir fiber/polymeric composite for the design of liquid storage tanks," Materials and Design, vol. 36, pp. 847-853, 2012.

[8] A. Duval, A. Bourmaud, L. Augier, and C. Baley, "Influence of the sampling area of the stem on the mechanical properties of hemp fibers," Materials Letters, vol. 65, no. 4, pp. 797-800, 2011.

[9] P. V. Joseph, K. Joseph, and S. Thomas, "Effect of processing variables on the mechanical properties of sisal-fiber-reinforced polypropylene composites," Composites Science and Technology, vol. 59, no. 11, pp. 1625-1640, 1999.

[10] S.-J. Kim, J.-B. Moon, G.-H. Kim, and C.-S. Ha, "Mechanical properties of polypropylene/natural fiber composites: 
comparison of wood fiber and cotton fiber," Polymer Testing, vol. 27, no. 7, pp. 801-806, 2008.

[11] M. M. Haque, M. Hasan, M. S. Islam, and M. E. Ali, "Physicomechanical properties of chemically treated palm and coir fiber reinforced polypropylene composites," Bioresource Technology, vol. 100, no. 20, pp. 4903-4906, 2009.

[12] G. Cantero, A. Arbelaiz, R. Llano-Ponte, and I. Mondragon, "Effects of fibre treatment on wettability and mechanical behaviour of flax/polypropylene composites," Composites Science and Technology, vol. 63, no. 9, pp. 1247-1254, 2003.

[13] B. F. Yousif and N. S. M. El-Tayeb, "High-stress three-body abrasive wear of treated and untreated oil palm fibre-reinforced polyester composites," Proceedings of the Institution of Mechanical Engineers J, vol. 222, no. 5, pp. 637-646, 2008.

[14] B. F. Yousif and N. S. M. El-Tayeb, "The effect of oil palm fibers as reinforcement on tribological performance of polyester composite," Surface Review and Letters, vol. 14, no. 6, pp. 1095$1102,2007$.

[15] N. S. M. El-Tayeb, "A study on the potential of sugarcane fibers/polyester composite for tribological applications," Wear, vol. 265, no. 1-2, pp. 223-235, 2008.

[16] N. Chand and U. K. Dwivedi, "Effect of coupling agent on abrasive wear behaviour of chopped jute fibre-reinforced polypropylene composites," Wear, vol. 261, no. 10, pp. 1057-1063, 2006.

[17] K. Sabeel Ahmed, S. S. Khalid, V. Mallinatha, and S. J. Amith Kumar, "Dry sliding wear behavior of $\mathrm{SiC} / \mathrm{Al}_{2} \mathrm{O}_{3}$ filled jute/epoxy composites," Materials and Design, vol. 36, pp. 306315, 2012.

[18] A. Shalwan and B. F. Yousif, "In state of art: mechanical and tribological behaviour of polymeric composites based on natural fibres," Materials Design, vol. 48, pp. 14-24, 2013.

[19] J. R. Mohanty, S. N. Das, H. C. Das, and S. K. Swain, "Effective mechanical properties of Polyvinyl alcohol biocomposites with reinforcement of date palm leaf fibers," Polymer Composite, vol. 34, no. 6, pp. 959-966, 2013.

[20] A. Sbiai, A. M. Abderrahim Maazouz, E. Fleury, H. Sautereau, and H. Kaddami, "Short date palm tree fibers / polyepoxy composites prepared using rtm process: effect of tempo mediated oxydation of the fibers," BioResources, vol. 5, no. 2, pp. 672-689, 2010.

[21] S. Mahdavi, H. Kermanian, and A. Varshoei, "Comparison of mechanical properties of date palm fiber-polyethylene composite," Bio-Resources, vol. 5, no. 4, pp. 2391-2403, 2010.

[22] K. M. M. Rao and K. M. Rao, "Extraction and tensile properties of natural fibers: vakka, date and bamboo," Composite Structures, vol. 77, no. 3, pp. 288-295, 2007.

[23] A. Alawar, A. M. Hamed, and K. Al-Kaabi, "Characterization of treated date palm tree fiber as composite reinforcement," Composites Part B, vol. 40, no. 7, pp. 601-606, 2009.

[24] F. A. Al-Sulaiman, "Date palm fibre reinforced composite as a new insulating material," International Journal of Energy Research, vol. 27, no. 14, pp. 1293-1297, 2003.

[25] S. Kalia, B. S. Kaith, and I. Kaur, "Pretreatments of natural fibers and their application as reinforcing material in polymer composites-a review," Polymer Engineering and Science, vol. 49, no. 7, pp. 1253-1272, 2009.

[26] M. S. Sreekala, M. G. Kumaran, S. Joseph, M. Jacob, and S. Thomas, "Oil palm fibre reinforced phenol formaldehyde composites: influence of fibre surface modifications on the mechanical performance," Applied Composite Materials, vol. 7, no. 5-6, pp. 295-329, 2000.
[27] B. F. Yousif and N. S. M. El-Tayeb, "Adhesive wear performance of T-OPRP and UT-OPRP composites," Tribology Letters, vol. 32, no. 3, pp. 199-208, 2008.

[28] P. K. Bajpai, I. Singh, and J. Madaan, "Tribological behavior of natural fiber reinforced PLA Composites,” Wear, vol. 297, pp. 829-840, 2013. 

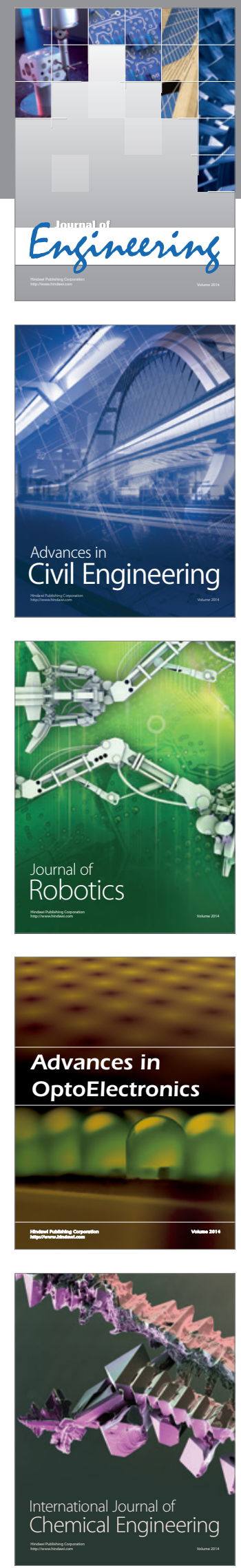

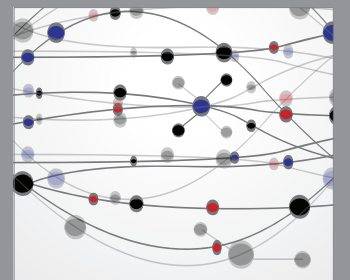

The Scientific World Journal
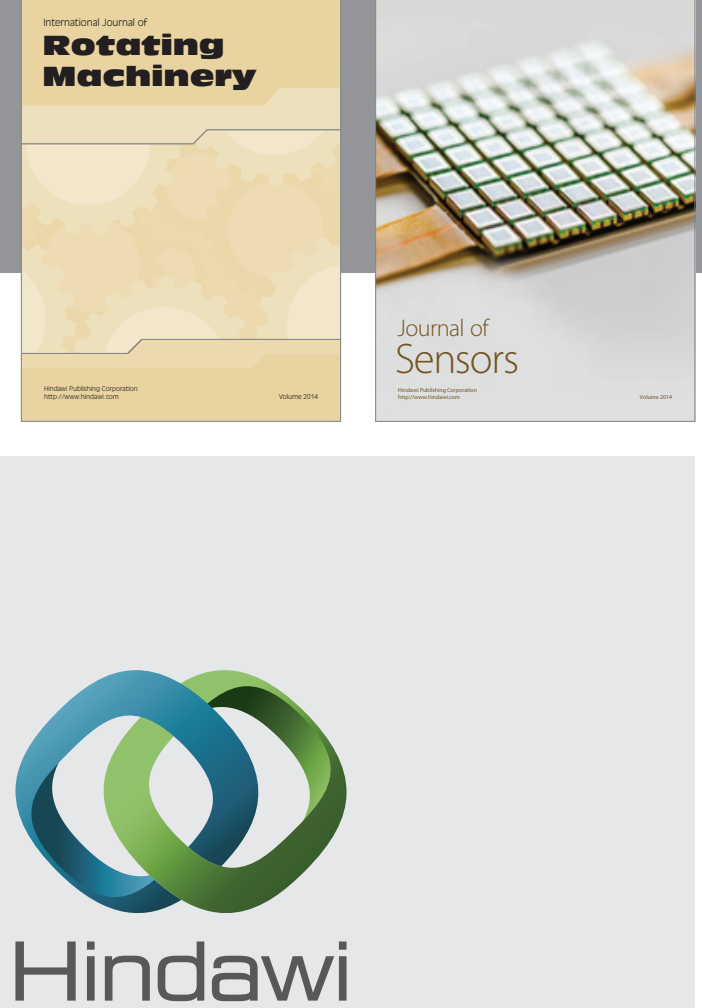

Submit your manuscripts at http://www.hindawi.com
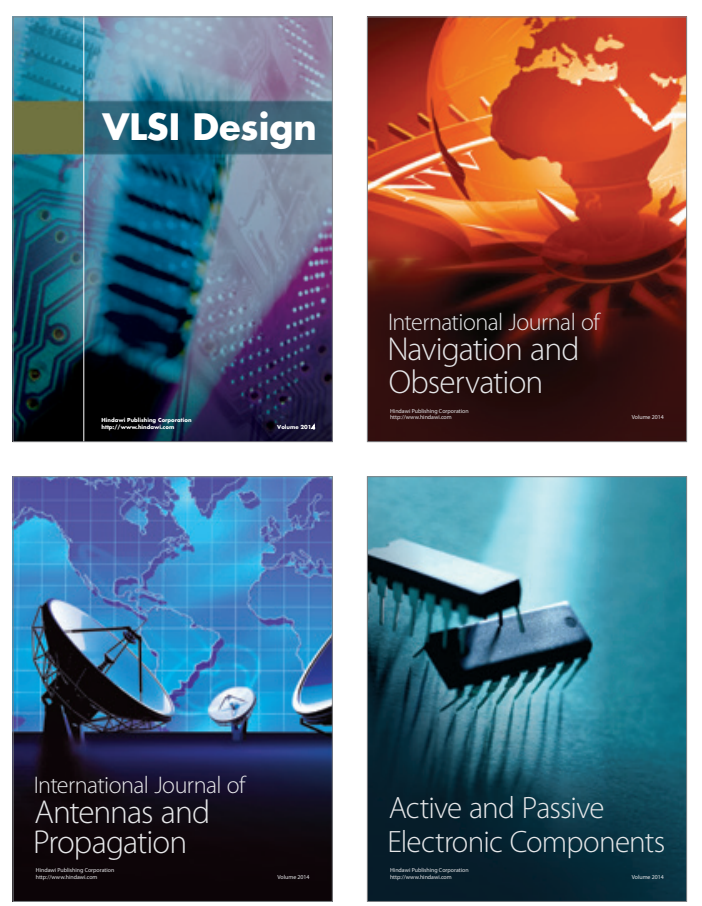
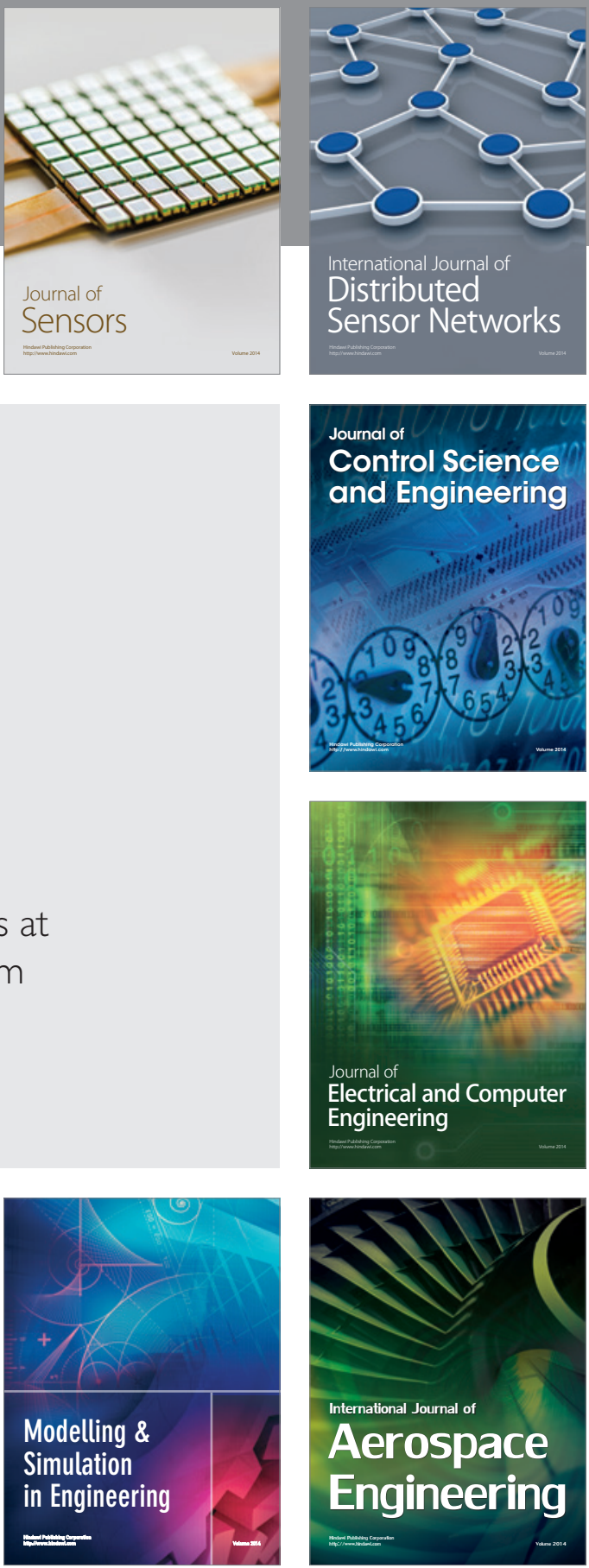

Journal of

Control Science

and Engineering
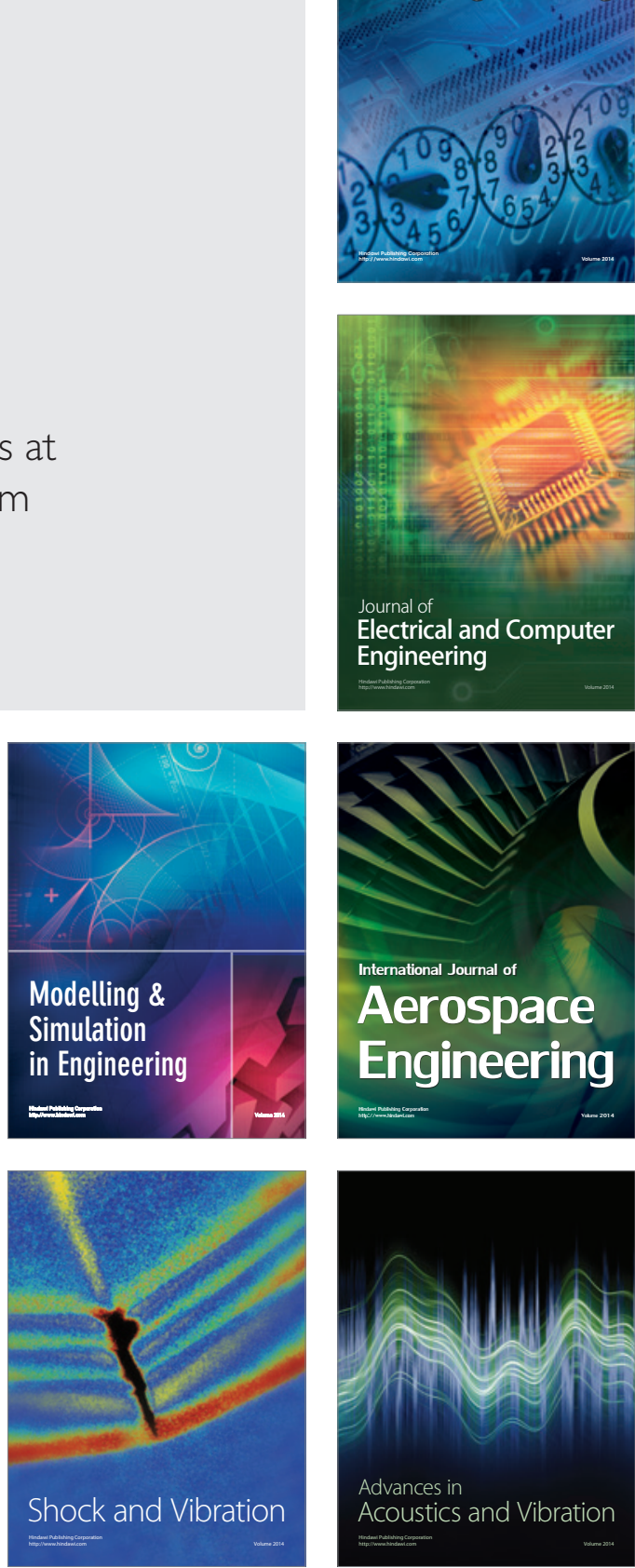